\title{
Flexural Behavior of Reinforced Concrete Beams Strengthened with BFRP Bars
}

\author{
G.N. Yang, B.R. Huo \\ College of Architectural and Civil Engineering Shenyang \\ University \\ No 21 Wanghua South Street Dadong District, Shenyang, \\ China
}

\author{
M.X. Zheng \\ Tianlang Real Estate Co Ltd Liaoning \\ No 227 Qingnian Street Shenhe District, Shenyang, China
}

\begin{abstract}
In order to strengthen buildings against various damages and prolong their service life, BFRP is considered serving as reinforcing materials instead of steel. Through static load tests on six simple supporting beams reinforced with BFRP rebar and six reinforced with steel rebar, the paper compares their flexural behavior, finds the load-deformation relationship of the BFRP reinforced concrete beam and finally concludes if the BFRP bar bonds well enough to concrete, it will be great strengthening materials, which is expected to improve the bearing capacity of beam specimens significantly. But in the experiment, the two materials fail to bond as well as assumed, which hinders the BFRP producing advantages as reinforcing materials. The BFRP rebar debonding from concrete restricts its application severely, so the first concern should be how to improve the technology for debonding-resistant BFRP rebar. Under the same loads, the deflections of all beam specimens are large, mainly due to the fact that the elastic modulus of the BFRP rebar is small, while its tensile strength is high, but not fully utilized, so the emphasis in design should be put on the use of pre-stressing tendons. Based on the experimental results, recommendations on relevant design and applications are of great importance to engineering practice and help improve the design guidance for fiber composite concrete structure.
\end{abstract}

Keywords-BFRP rebar; flexural; load-deformation relationship; debonding

\section{INTRODUCTION}

In recent years, the use of basalt fiber reinforced polymer (BFRP) as a means of rehabilitating or strengthening reinforced concrete (RC) beams has generated much interest in the construction industry. Compared with tendon, the BFRP textile fiber has higher tensile strength, higher corrosion resistance, lower density, higher fatigue resistance, better insulation and some other merits. Obviously, if the BFRP is used as replacement for tendon in reinforced concrete structures, reinforcing bar corrosion can be avoided thoroughly. High stiffness-to-weight and strength-to- weight ratios of these materials combined with their superior environmental durability have made them a competing alternative to the conventional strengthening and repair materials. In addition, it is a now type of green fiber composite material, pollution-free, non-carcinogenic and eco-friendly. Basalt fiber is a relative newcomer to fiber reinforced polymers (FRPs).At present, numerous research studies have been performed on carbon fiber and glass fiber reinforced concrete, while studies on concrete slabs reinforced with BFRP are limited. The mechanical properties of BFRP rebar, such as linear elastic stress-strain relationship and low elastic modulus, differ from those of steel slab greatly. It is significant to study the flexural behaviors and design theory of BFRP reinforced concrete beams, which helps design concrete beams with higher load capacity and durability, avoiding disastrous damages significantly. Experimental studies on BFRP reinforced concrete beams have made some progress, but there is still a long way ahead. The main contents of the present thesis are briefly summarized as following: 1. six simple-supported beams reinforced with BFRP rebar and six reinforced with steel rebar were tested on the three-point static load, and analyzed the results. 2. BFRP reinforced beams were tested on the ultimate load. 3 . based on the test results, the load-deformation relationship of BFRP reinforced beams were analyzed.

\section{EXPERIMENTAL PROGRAM OF FLEXURAL BEHAVIOR OF BFRP REINFORCED CONCRETE BEAMS}

The experiment consisted of two groups of beams. Beams of group one, M1,M2 and M3, were strengthened with steel rebar, while those of group two, M4,M5, and M6, were strengthened with BFRP rebar. Two test specimens were made from each sample beam with sectional dimension $200 \times 300$ $\mathrm{mm}$, beam length $2060 \mathrm{~mm}$, and clear span $1800 \mathrm{~mm}$, simple supported at both ends. Details of the parameters are given in Table 1. The beam structure is shown in Figure 1. The BFRP rebar used in the tests was manufactured by ShangHai Russia \& Gold Basalt Fiber CO., LTD.

TABLE I DETAILS OF TEST SPECIMENS.

\begin{tabular}{cccccc}
\hline $\begin{array}{c}\text { Beam } \\
\text { Num. }\end{array}$ & $\begin{array}{c}\text { Concrete } \\
\text { strength }\end{array}$ & $\begin{array}{c}\text { Upper } \\
\text { rebar }\end{array}$ & $\begin{array}{c}\text { Lower } \\
\text { rebar }\end{array}$ & $\begin{array}{c}\text { Steel } \\
\text { stirrup }\end{array}$ & $\begin{array}{c}\text { Reinforce } \\
\text { ment } \\
\text { ratio(\%) }\end{array}$ \\
\hline M1-1,2 & $\mathrm{C} 20$ & $2 \Phi 12$ & $\mathrm{~S} 2 \Phi 11$ & $\Phi 5 @ 80$ & 0.36 \\
$\mathrm{M} 2-1,2$ & $\mathrm{C} 30$ & $2 \Phi 12$ & $\mathrm{~S} 2 \Phi 16$ & $\Phi 5 @ 80$ & 0.77 \\
M3-1,2 & $\mathrm{C} 40$ & $2 \Phi 12$ & $\mathrm{~S} 3 \Phi 16$ & $\Phi 5 @ 80$ & 1.15 \\
M4-1,2 & $\mathrm{C} 20$ & $2 \Phi 12$ & $\mathrm{~B} 2 \Phi 11$ & $\Phi 5 @ 80$ & 0.36 \\
M5-1,2 & $\mathrm{C} 30$ & $2 \Phi 12$ & $\mathrm{~B} 2 \Phi 16$ & $\Phi 5 @ 80$ & 0.77 \\
$\mathrm{M} 6-1,2$ & $\mathrm{C} 40$ & $2 \Phi 12$ & $\mathrm{~B} 3 \Phi 16$ & $\Phi 5 @ 80$ & 1.15 \\
\hline
\end{tabular}

Note: S-steel reinforcement B-BFRP reinforcement

\section{A. Experimental Loading and Test}

Loading device of the sample beam is shown in Figure 1. 
The sample beam bears the three-point concentrated load transferred by the distributive beam over which a jack is set up. In order to avoid local stress concentration or even local concrete crush, pads are put on the beam bearing and three-point bend. Replacement meter monitors the settlement of middle span and abutment and strain gage measures strain on beam section at different heights. The test is conducted under step load, with unit load of $5 \mathrm{KN}$ before appearance of concrete crack and unit load of $3 \mathrm{KN}$ after that. The load holding duration is 2 min, meanwhile experimental data is recorded. When the crack grows to some extent, change the loading way from step loading to sustained loading until the concrete sample is crushed and test specimens damaged.

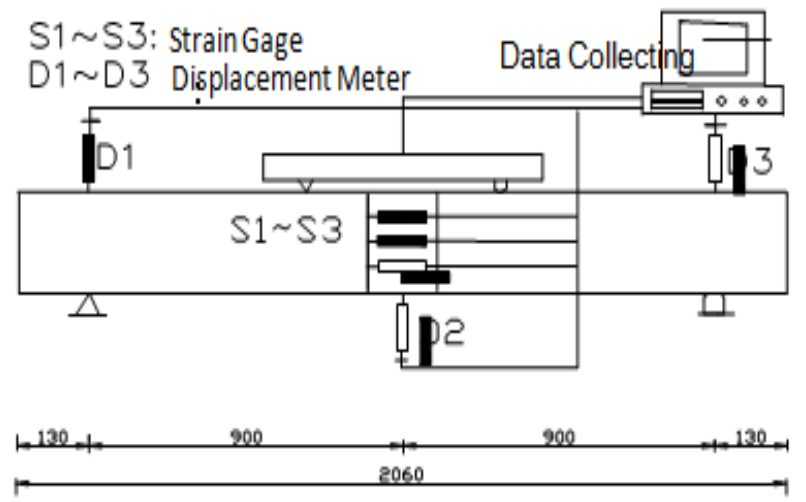

FIGURE I. LOADING TEST SET-UP(UNITS: MM).

\section{EXPERIMENTAL RESULTS AND ANALYSIS}

\section{A. Crack Development in BFRP Reinforced Concrete Beam}

a. Conduct test under step load until crack appears. During this period, since there is no crack in concrete beam, the total cross section is loaded. Concrete beam is characteristic of elastic deformation at low deformation rate, which means stress and strain are proportional. The load-deflection relationship is linear.

b. As the load increases, the tensile strain reaches its utmost limit on the concrete's edge. In this case, the tensile stress approaches tensile strength of the test specimen and cracks begin to appear on the weakest stress section of concrete beam. With cracks on the cross section, concrete slab under strain stop working and, correspondingly, strain on this area is transferred to BFRP rebar. Obviously, stress is redistributed. Tensile stress increases with the increasing of load. Because of low elastic modulus of BFRP rebar, cracks develop very quickly. The area of concrete sample under stress decreases, while the growth rate of deflection increases. Although curve slope is much smaller due to yield, the curve is approximately linear. With sustainedly increasing of load, the sample concrete under stress is crushed while the BFRP rebar being tested doesn't reach its nominal yield point. Therefore, failure in BFRP reinforced concrete beam occurs, when concrete under stress is crushed, much earlier than the BFRP in tensile area reaches its ultimate tensile strength, which tends to cause failure in high-reinforcement-ratio beam.

As load increases continuously, deflection value of BFRP reinforced concrete beam increases greatly, cross section is deformed rapidly and reaches its ultimate deformation, which is one of the main causes of structure failure. Based on relevant theories and experimental analysis, failure in BFRP reinforced concrete beam occurs in three cases. The first, when the structure is designed to be high-reinforcement-ratio beam, concrete under stress is crushed, namely, failure in high-reinforcement-ratio BFRP reinforced concrete beam; the second, when the structure is designed to be middle-reinforcement-ratio beam, BFRP reinforced concrete beam is deformed greatly, causing structure failure, namely, failure in middle-reinforcement-ratio BFRP reinforced concrete beam; the third, when FPR rebar is fractured, brittle failure occurs, abruptly and with no warning signs, namely, failure in low-reinforcement-ratio concrete beam.

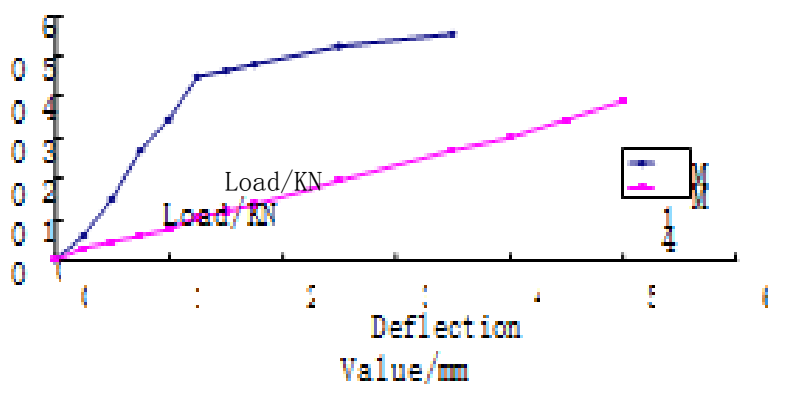

FIGURE II. M1,M4 BEAMS’ LOAD-DEFLECTION CURVE.

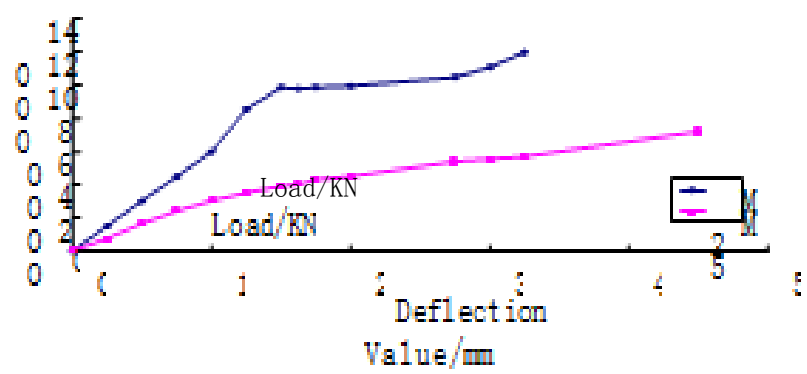

FIGURE III. M2,M5 BEAMS’ LOAD-DEFLECTION CURVE.

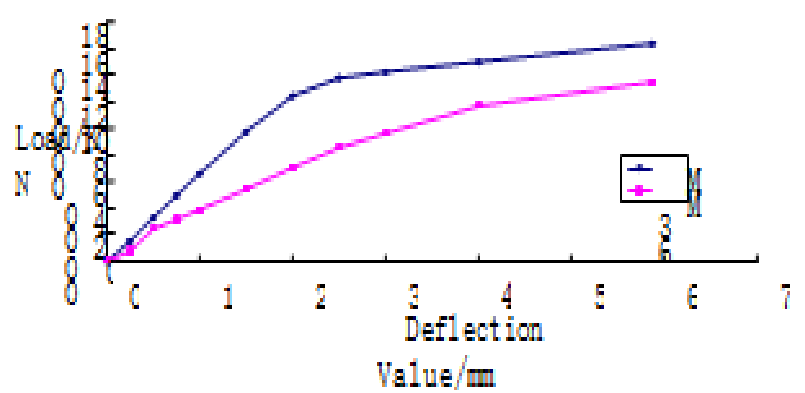

FIGURE IV. M3,M6 BEAMS’ LOAD-DEFLECTION CURVE.

Specimens M1 \& M4, specimens M2 \&M5, specimens M3 \& M6 are of the same enforcement ratio respectively, with same concrete strength, but different types of longitudinal bars inside. As shown in Figure 2 Figure 3 and Figure 4, reinforced concrete beam strengthened with BFRP bar, marked M1 M2 and M3, and ordinary reinforced concrete beam, marked M4 
M5 and M6, are tested and compared. At the beginning of loading, stress on M1 M2 and M3 increase quickly but deflection of them increase slowly, while as for M4 M5 and M6, the opposite is true. The reason is analyzed as follows: bonding strength between BFRP bar and concrete was overestimated in designing. As a matter of fact, bonding strength doesn't come up to expectation. As load is being exerted, slip occurs, which results in cracks widening and, ultimately, beam failure. While considering BFRP bar, a new type of building material, as the replacement of reinforcing steel to bear longitudinal stress, the major concerns are how to enhance bonding strength between BFRP bar and concrete, how to improve production technology, and how to produce high-bonding-strength BFRP rebar.

\section{B. Comparing the Theoretical Values and Experimental Values of Sample Beams' Deflection}

The comparison is based on the calculating formula of FRP-strengthened-concrete beams' deflection, proposed by Cangarao. In the formula, assumed concrete slab under load cracks significantly, cracking equivalent moment of inertia $I_{c r}$ is applied to central beam, and ACI formula is applied to calculate $I_{c r}$ of top section, then the moment of inertia is calculated as follows:

$$
I_{e}=\frac{23 I_{c} I_{c r}}{8 I_{c r}+15 I_{c}}
$$

Apply the present formula to obtain value of the inertia moment, and insert it into the formula of mid-span deflection, the result is as follows:

$$
\Delta_{\max \text { imum }}^{\text {midspan }}=\frac{p l_{1}}{E_{c}}\left(\frac{4 l_{1} l_{2}+l_{2}^{2}}{8 I_{c r}}+\frac{l_{1}^{2}}{3 l_{e}}\right)
$$

The result shows that experimental data of BFRP reinforced concrete beam's loading capacity agrees well with theoretical values.

\section{SUMMARY}

If bonding between them is strong enough, BFRP rebar and concrete should co-work properly, and consequently the loading capacity of beam specimens should be improved greatly. But during the test, bonding between BFRP and concrete is not as strong as expected, therefore results of the test fail to embody BFRP bar's advantage in strength. BFRP rebar's debonding from concrete restricts its application severely, so the first concern should be improving the technology for debonding resistant BFRP rebar. Under the same loads, the deflections of the beam specimens are all large, mainly due to the fact that the elastic modulus of the BFRP rebar is small, while its tensile strength is high, but not fully utilized, so the emphasis in design should be put on the use of pre-stressing tendons. Based on the experimental results, recommendations on relevant design and applications are of great importance to engineering practice and help improve the design guidance for fiber composite concrete structure.

\section{REFERENCES}

[1] Baorong Huo. Theoretical and Experimental Study on BFRP Concrete Structure [D]. Doctor Paper of Liaoning Technical University, 2011:29-43.

[2] Kelley L, Michal L. Design philosophy for structural strengthening with FRP [J]. Concrete International, 2000, (2) :77-82.

[3] Xue Weichen, Wang Xiaohui, Zhang Shulu. Bond properties of high strength CFRP strands[J]. ACI Material Journal, 2008, 105(1):303311.

[4] ACI Committee 440. State-of-the-Art-Report on Reinforced Plastic for Concrete Structures. Detroit, Michigan: American Concrete Institutes February, 1996.

[5] KWON I B, KIM C Y, CHOIM Y. Distributed strain and temperature measurement of a beam using fiber optic BOTDA sensor [J]. Proceeding of SPIE, 2003, 50( 57):486-496.

[6] ALAHHAB I M, CHO Y T, NEW SON T P. Comparison of the methods for discriminating temperature and strain in spontaneous Brillion based distributed sensors [J]. Optics Letters, 2004, 29(1):26-28.

[7] Kelley L, Michal L. Design philosophy for structural strengthening with FRP [J]. Concrete International, 2000, (2):77-82. 